\title{
25 Hydroxy Vitamin D Level, Bone Health, Vitamin D and Calcium Intake in Chilean Patients with Phenylketonuria and Hyperphenylalaninemias
}

Journal of Inborn Errors of Metabolism \& Screening 2021, Volume 9: e20210004 DOI: https://doi.org/10.1590/2326-4594JIEMS-2021-0004

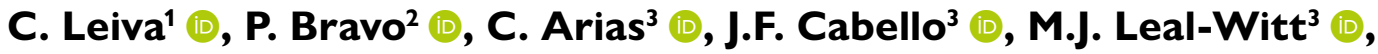 \\ F. Salazar ${ }^{3}$ (i) and V. Cornejo ${ }^{3}$
}

\begin{abstract}
It has been shown that there is a decrease in the concentrations of 25 hydroxyvitamin D (25-OHD) and bone mineral density (BMD) in patients with phenylketonuria (PKU) in their follow-up. Our objective was to determine concentrations of 25-OHD in subjects with PKU and hyperphenylalaninemia (HPA). Transversal analytical study considered three groups: G1-PKU with neonatal diagnosis and formula intake without Phe; G2-HPA, without specific treatment and G3-C control group. Sixteen patients per group (aged 6-23) were included. Levels of 25-OHD, lumbar spine (L2-L4), femur and total BMD, intact parathormone (PTH) and vitamin D (VitD) and calcium intake were calculated. The Kruskal-Wallis statistical test was applied $(p$-value<0,05). Significant differences were detected in concentrations of 25-OHD between G1-PKU and G2-HPA (38.9 ng/mL; $28 \mathrm{ng} / \mathrm{mL}$, respectively) (NV: $>30 \mathrm{ng} / \mathrm{mL}$ ). G1-PKU had a higher intake of VitD, with differences among groups. There were no significant differences among groups in relation to BMD and intact PTH. In conclusion, G1-PKU under treatment and with good adherence, does not present VitD deficiency and no BMD alterations are observed. In contrast, G2-HPA had a lower intake of VitD and decreased 25-OHD concentrations which could affect the bone architecture in the long term. Further studies on the G2-HPA are suggested.
\end{abstract}

Keywords: phenylketonuria, vitamin D and bone mineral density.

\section{Introduction}

Hyperphenylalaninemia (HPA) is produced by the deficit or absence of the enzyme phenylalanine hydroxylase $(\mathrm{PAH})$ encoded in gene 12q22-q24.1, causing accumulation of phenylalanine (Phe) in plasma and tissues, and decreased synthesis of tyrosine (Tyr), which causes intellectual disability without diagnosis and treatment. Phenylketonuria (PKU) is the most severe form of presentation, whose treatment consists of a Phe restricted diet, prohibition of foods of animal origin, and request of supplementation with a protein substitute (PS) without Phe. HPAs do not require diet treatment, only monitoring of Phe concentrations. The overall worldwide prevalence of the disease is 6.002 per 100,000 neonates (95\% confidence interval, 5.07; 6.93) [1]. In Chile, it is $1: 18,916$ for PKU and 1:10,198 newborn (NB) for HPA [2].

Patients with PKU, due to lifelong nutritional treatment, receive most of their protein, vitamin $\mathrm{D}$ (VitD) and calcium intake through PS without Phe, which has been fortified with vitamins and minerals [3]. Kose E. and Arslan N., found VitD deficiency in $53.6 \%$ of patients with PKU and in $47.2 \%$ of the control group [4]. A study carried out on 28 PKUs aged between 10 and 33 years old, on a strict diet, osteopenia was detected in 14 patients [5], with a similar prevalence found by other authors (50\%) [6]. Another study found severely decreased lumbar BMD (z-score less than (-2) standard deviations (SD)), in $4.9 \%$ of patients. None of these patients had osteoporosis, and the prevalence of fractures was comparable to that of the general population (41.7\% versus $38.2 \%)$ [7].

\footnotetext{
${ }^{1}$ Pontificia Universidad Católica de Chile, Facultad de Medicina, Departamento de Ciencias de la Salud, Santiago, Chile.

${ }^{2}$ Clínica Universidad de los Andes, Clínica Santa María, Las Condes, Región Metropolitana, Chile.

${ }^{3}$ Universidad de Chile, Instituto de Nutrición y Tecnología de los Alimentos, Laboratorio de Genética y Enfermedades Metabólicas, Santiago Chile.
}

Received January 20, 2021, and in revised form June 8, 2021. Accepted for publication June 14, 2021.

\section{Corresponding Author:}

V. Cornejo, Email: vcornejo@inta.uchile.cl. 
Considering that VitD deficiency causes bone diseases, such as rickets in children and osteomalacia in adults, and has been associated with increased risk of fractures [8], VitD is considered a hormone as it has receptors on virtually every cell in the human body [9]. There is also an association with cardiovascular and autoimmune diseases [10], cancer [11], respiratory infections [12], and brain function [13].

The main aim of this study was to determine the concentrations of 25-OHD in children and adults with PKU and in HPA, diagnosed in the neonatal period and in follow-up, and to compare them with a control group.

\section{Methods}

\section{Patients}

A cross-sectional observational study that was carried out based on data obtained from a total of 16 Chilean PKU patients of both sexes from 6 to 23 years old. For the calculation of the sample size, Stata 12.0 software was used with a power of $80 \%$, alpha $=5 \%$, prevalence of osteopenia in healthy individuals of $2 \%[14,15]$ and prevalence of osteopenia in PKU patients of 50\% [16], according to bibliographic review. With these values, a sample size of 16 participants was obtained for each of the three groups. Group 1 was defined as: 16 subjects with PKU (G1-PKU), with neonatal diagnosis, the average of Phe concentration at diagnosis was $1206 \pm 595 \mathrm{umol} / \mathrm{L}$ (95\% CI 847 - 1566), and during treatment they maintain Phe concentrations between 268-485 umol/L (95\% CI). Group 2: 16 subjects with HPA (G2-HPA), with an average of Phe concentration at diagnosis of $181 \pm 54 \mathrm{umol} / \mathrm{L}$ (95\% CI 153 - 210), without requiring a dietary treatment, only monitoring Phe concentrations, and Group 3 control (G3-C): 16 control subjects. The G3-Control was matched by age, sex, and nutritional status with G1-PKU and G2-HPA. The study was carried during summer and all participants lived in Santiago, Chile. The distribution of the groups was homogeneous in terms of age and sex, and the following were excluded: pregnant women, people with diseases related to bone metabolism and cases with unsigned informed consent. The study was approved by the ethics committee of INTA University of Chile, and it was conducted in accordance with the principles of the declaration of Helsinki (approval date March $10^{\text {th }}, 2014$ ).

Phe concentrations in follow-up: Phe was quantified by fluorometry using blood spots on a filter paper card. The appropriate Phe concentrations for children under two years old was considered to be between 120-240 umol/L and for over two years of age between 120-360 umol/L, according to the Chilean protocol for PKU[17].

Assessment of nutritional status: Weight (kg) and height (cm) were used, both measured on a scale (i.e., Seca) with an accuracy of $0.05 \mathrm{~kg}$, and a stadiometer with a margin of error of $0.01 \mathrm{~cm}$. The body mass index (BMI) $(\mathrm{kg} / \mathrm{m} 2)$ was calculated. To classify the nutritional status in children between 6 and 18 years old, the anthropometric standards according to age and sex of the World Health Organization (WHO) 2007 [18] were used as a standard reference, whereas in adults the standards of the Chilean Ministry of Health endorsed by the WHO were used according to age and sex [19].

Physical activity: In 19 patients, the short version of the International Physical Activity Questionnaire (IPAQ) [20] was carried out, focused on people between 15 and 69 years old. In the remaining patients $(n=29)$, the level of physical activity was measured using the Physical Activity Questionnaire for Children (PAQ-C)[20] focused on children of ages 8-14.

Measurement of 25 hydroxy-vitamin D (25-OHD): There is a consensus in the literature to use the measurement of the 25-OHD marker in serum as an index of the status or total body deposition of VitD, since 25-OHD is the most abundant metabolite of VitD in serum and has a long half-life of more than 15 days. For cut-off points, the recommendations of the American Society of Endocrinology were considered, which defines as 25-OHD cut-off points: severe deficiency $<12 \mathrm{ng} / \mathrm{mL}$, deficiency $<20 \mathrm{ng} /$ $\mathrm{mL}$, insufficiency $21-29 \mathrm{ng} / \mathrm{mL}$ and sufficiency $>30 \mathrm{ng} / \mathrm{mL}[21]$.

Measurement of Bone Mineral Density (BMD): BMD was measured: lumbar spine (L2 and L4), femur and total through the DPX-L Lunar densitometer (Lunar corporation, Madison Wisconsin, US). In this study, the z-score was used as a diagnostic criterion, as the participants were under 25 years old. The reference parameter was the American data published by Heidi J. et al., and established in the international consensus on bone densitometry, as American standards[22]. The ranges of normality in the pediatric population are not clearly defined as in the adult population [23], however, the same cut-off points are used for this population [24] by consensus. In this study, a BMD was classified as normal when the $\mathrm{z}$-score was between $(-1)$ and (+1), slightly decreased BMD with a $z$-score between $(-2)$ and $(-1)$ and as severely decreased BMD with a low Z-score (-2) [25].

Measurement of body composition: Through DEXA (Dual Energy X-ray Absorptiometry) the body composition was also determined: fat mass and fat-free mass.

Measurement of intact parathyroid hormone: This hormone is a direct measure of the function of the parathyroid gland, independent of the kidney function. A normal concentration is considered to be between $15-60 \mathrm{pg} / \mathrm{mL}$; since over $60 \mathrm{pg} /$ $\mathrm{mL}$ the risk of hypercalcemia increases with the consequent decrease of BMD [26].

Estimated intake of calcium, vitamin D and phenylalanine: Food intake was assessed through a 24-hour dietary recall, threedays-a-week. Calcium (Ca) and VitD intake were compared with the estimated average requirement (EAR) and the normal range was considered between $90-110 \%$ of that value. The intake of Phe was compared with the daily intake according to the Chilean protocol established according to age, weight, and metabolic state [27]. The Chilean nutritional composition guide and the amino acid analysis program available at the laboratory for this study were used to estimate nutrient intakes [28]. 
Statistical analysis: A descriptive analysis of the variables was carried out, establishing the distribution of the subjects according to $\mathrm{z}$-score categories and normal ranges in each study group. In the groups studied, each one was characterized according to the median and $95 \%$ confidence interval (CI) of each of the study variables.

For the comparison among groups, a non-parametric statistical test was considered (i.e., Kruskal-Wallis) in order to determine the differences among G1-PKU, G2-HPA and G3-C, with respect to each variable studied. In addition, the statistical analysis was carried out categorizing by sex and by pubertal stage to check the differences. Finally, to determine the differences between the groups, the Mann-Whitney test was used. A p-value $<0.05$ was considered as significant.

\section{Results}

No statistically significant differences were found by nutritional status and body composition with respect to fat mass and fatfree mass among the three study groups (Table 1). Regarding physical activity, the distribution was similar in the three groups, 36 patients were sedentary and 12 were physically active. Table 1 also shows the distribution of subjects according to sex, age, nutritional status and Phe concentrations, with a similar distribution for the first three variables in the three groups.

To begin with, the results are described according to distribution in the three groups of study. There values are represented in Table 2 by the median, 95\% confidence interval (CI), and the $p$ value (Kruskall-Wallis) of the three groups: concentrations of 25-OHD, column, femoral and total BMD for the biochemical markers of bone turnover (PTH) and for the intake of VitD, Ca, and Phe.
Regarding the metabolic state of $25-\mathrm{OHD}$, it was observed that G1-PKU had a median of $38.9 \mathrm{ng} / \mathrm{mL}$ (95\% CI, 33.9; 43.2) and G2-HPA of $28.1 \mathrm{ng} / \mathrm{mL}$ (95\% CI, 24.7; 33.2); this difference is significant $(\mathrm{p}<0.05)($ Table 2$)$. When comparing the distribution of the 25-OHD concentrations in the different groups with the recommendations of the Endocrine Society of the United States, it was observed that two patients of the G1-PKU, ten patients of the G2-HPA and six subjects of the G3-C presented deficiency of $25-\mathrm{OHD}(<20 \mathrm{ng} / \mathrm{mL}$ ) (Figure 1).

The results obtained for lumbar spine, femur and total BMD showed no statistically significant differences between the three study groups (Figure 2). The median z-score of lumbar spine BMD detected in the G1-PKU was of $(-0.3)$ (95\% CI, (-0.7); $(+0.3))$, in G2-HPA of $(+0.05)$ (95\% CI, $(-0.3) ;(+0,7))$ and in G3-C of (-0.4) (95\% CI, (-0.7); (+0.32)) (Table 2 and Figure 2).

The Phe concentration detected in G2-HPA was a median of $164 \mathrm{umol} / \mathrm{L}(95 \% \mathrm{CI}, 138 ; 188)$ and in the G1-PKU of $310 \mathrm{umol} / \mathrm{L}$ (95\% CI, 262; 481). Considering that the recommended metabolic value per protocol is to keep the Phe concentrations in blood between 120 and $360 \mathrm{umol} / \mathrm{L}$, it was observed that 10 patients of the G1-PKU had a concentrations within the acceptable range and six cases values over $360 \mathrm{umol} / \mathrm{L}$ of Phe, being $768 \mathrm{umol} / \mathrm{L}$ the maximum value of Phe.

In assessing VitD intake, it was found that G1-PKU had an average daily intake of $400 \mathrm{IU} /$ day $(95 \% \mathrm{CI}, 374 ; 567)$ of VitD, G2-HPA of 150 IU/day (95\% CI, 119; 213) and G3-C of 145 IU/ day $(95 \% \mathrm{CI}, 134 ; 216)$, with statistically significant differences between G1-PKU and G2-HPA ( $\mathrm{p}<0.05)$ and between G1-PKU and $\mathrm{G} 3-\mathrm{C}(\mathrm{p}<0.05)$ (Figure 3).

In relation to $\mathrm{Ca}$ intake, it was possible to detect that G1PKU consumed an average of 2,487 mg/day (95\% CI, 1831;

Table 1. Distribution of subjects according to age, sex, nutritional status, and blood phenylalanine level.

\begin{tabular}{|c|c|c|c|}
\hline Variable/Group & $\begin{array}{c}\text { G1-PKU } \\
n=16\end{array}$ & $\begin{array}{c}\text { G2-HPA } \\
n=16\end{array}$ & $\begin{array}{l}G 3-C \\
n=16\end{array}$ \\
\hline Male & 9 & 9 & 9 \\
\hline \multicolumn{4}{|c|}{ Age (n) } \\
\hline Prepuberal & 9 & 12 & 7 \\
\hline $\begin{array}{l}\text { Risk of malnutrition } \\
\text { Z-Score BMI/age (<O=-1DS and }>-2 D S)\end{array}$ & 0 & 0 & 1 \\
\hline $\begin{array}{l}\text { Normal } \\
\text { Z-Score BMI/age (>-1DS y <+1DS) }\end{array}$ & 7 & 8 & 9 \\
\hline $\begin{array}{l}\text { Overweight } \\
\text { Z-Score BMI/age (>o=+1DS } y<+2 D S)\end{array}$ & 7 & 5 & 5 \\
\hline High; out of control range (>375 umol/L) & 6 & 0 & ND \\
\hline
\end{tabular}

Abbreviations: The table represents the number of subjects per group. PKU: Phenylketonuria, HPA: Hyperphenylalaninemia, BMI: body mass index, ND: no data. 
Table 2. Characteristics of the dependent variables according to study groups.

\begin{tabular}{|c|c|c|c|c|c|c|c|c|}
\hline \multirow{3}{*}{$\begin{array}{l}\text { Variables/groups } \\
\text { Distribution }\end{array}$} & \multicolumn{8}{|c|}{ Description of variables by study group } \\
\hline & \multicolumn{2}{|c|}{ G1-PKU } & \multicolumn{2}{|c|}{ G2-HPA } & \multicolumn{2}{|c|}{ G3-C } & \multicolumn{2}{|c|}{ P VALUE } \\
\hline & Median & $95 \% \mathrm{Cl}$ & Median & $95 \% \mathrm{Cl}$ & Median & $95 \% \mathrm{Cl}$ & $\begin{array}{l}\text { P VALUE } \\
\text { Kruskal- } \\
\text { Wallis }\end{array}$ & $\begin{array}{l}\text { P VALUE } \\
\text { Post-hoc } \\
\text { test }\end{array}$ \\
\hline $25-\mathrm{OHD}(\mathrm{ng} / \mathrm{mL})$ & 38.9 & $(33.9 ; 43.2)$ & 28.1 & $(24.7 ; 33.2)$ & 33.0 & $(29.6 ; 38.1)$ & $P<0.05$ & $\begin{array}{c}\mathbf{p}<\mathbf{0 . 0 5} \\
\text { Between } \\
\text { G1-PKU } \\
\text { and G2-HPA }\end{array}$ \\
\hline Lumbar spine BMD (SD) & -0.3 & $(-0.7 ; 0.3)$ & 0.05 & $(-0.3 ; 0.7)$ & -0.4 & $(-0.7 ; 0.32)$ & 0.3 & $\mathrm{~N} / \mathrm{SD}$ \\
\hline Right femoral neck BMD (SD) & -0.3 & $(-0.4 ; 0.8)$ & 0.65 & $(0 ; 1.3)$ & 0.2 & $(-0.04 ; 0.62)$ & 0.27 & $\mathrm{~N} / \mathrm{SD}$ \\
\hline Total BMD (SD) & 0.2 & $(-0.1 ; 0.9)$ & 1.25 & $(0.47 ; 1.43)$ & 0.5 & $(-0.03 ; 0.82)$ & 0.08 & $\mathrm{~N} / \mathrm{SD}$ \\
\hline Intact PTH (pg/mL) & 30.9 & $(27.4 ; 44.6)$ & 30.8 & $(28.6 ; 38.2)$ & 33.8 & $(31.3 ; 40.9)$ & 0.5 & $\mathrm{~N} / \mathrm{SD}$ \\
\hline VitD intake (IU) & 400 & $(374 ; 567)$ & 150 & $(119 ; 213)$ & 145 & $(134 ; 216)$ & $P<0.05$ & $\begin{array}{c}\mathbf{P}<\mathbf{0 . 0 5} \\
\text { Between } \\
\text { G1-PKU } \\
\text { and G3-C } \\
\text { G1-PKU } \\
\text { and G2-HPA }\end{array}$ \\
\hline $\begin{array}{l}\text { Total Calcium Intake (mg) / } \\
\text { Supplemental Calcium Intake (mg) }\end{array}$ & $2487 / 1000$ & $\begin{array}{c}(1831 ; \\
2507) \\
/(666 ; 1000)\end{array}$ & 744 & $(610 ; 991)$ & 978 & $(724 ; 1032)$ & $P<0.05$ & $\begin{array}{c}\mathbf{P}<\mathbf{0 . 0 5} \\
\text { Between } \\
\text { G1-PKU } \\
\text { and G3-C } \\
\text { G1-PKU } \\
\text { and G2-HPA }\end{array}$ \\
\hline Phe intake (mg) & 441 & $(365 ; 541)$ & 3198 & $\begin{array}{l}(2805 \\
3590)\end{array}$ & 3765 & $\begin{array}{l}(3299 \\
4150)\end{array}$ & $p<0.05$ & $\begin{array}{c}\mathbf{P}<\mathbf{0 . 0 5} \\
\text { Between } \\
\mathrm{G} 1-\mathrm{PKU} \\
\text { and G3-Cl } \\
\mathrm{G} 1-\mathrm{PKU} \\
\text { and G2- HPA }\end{array}$ \\
\hline Phe concentration (umol/L) & 310 & $(262 ; 481)$ & 164 & $(138 ; 188)$ & ND & ND & ND & $\mathrm{N} / \mathrm{SD}$ \\
\hline
\end{tabular}

Values represented by the median and $95 \%$ confidence interval $(\mathrm{Cl})$, most of them had a non-normal distribution.

Abbreviations: PKU: Phenylketonuria, BMD: Bone mineral density, PTH: Parathyroid hormone, Phe: Phenylalanine, 25-OH-Vitamin D: 25-OHD, VitD: Vitamin D. Group 1: PKU. Group 2: HPA. Group 3: Control, No data: ND.

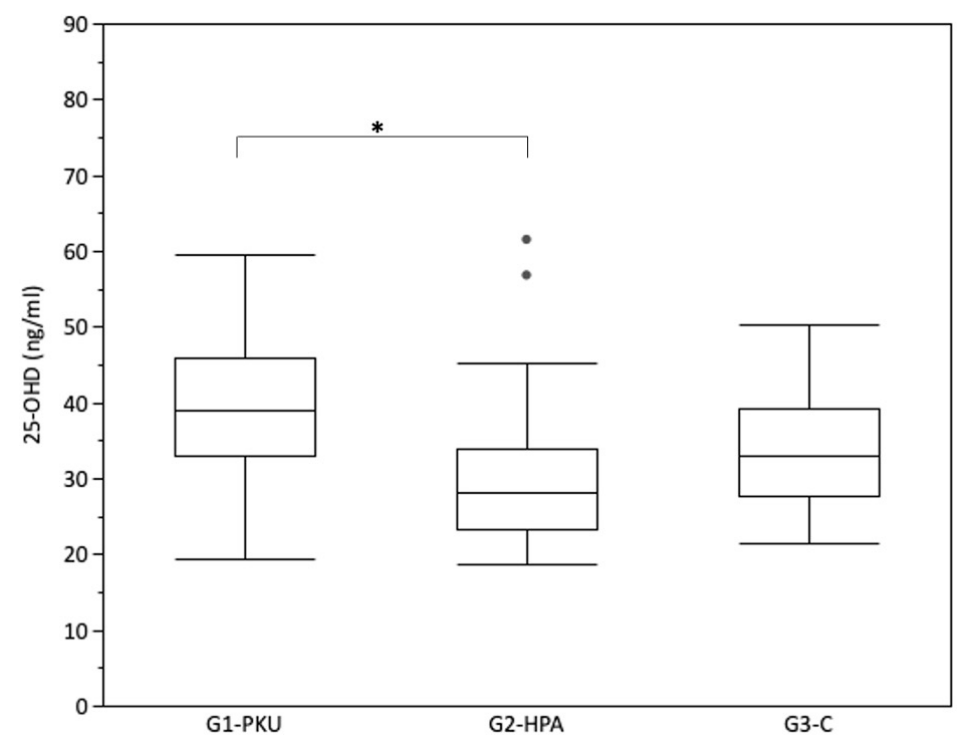

Figure 1. Plasma concentration 25-OHD (ng/mL) in each group. Plasma 25-OHD concentration in three groups of patients: Group 1: PKU, Group 2: HPA and Group 3: Control $(n=48)$. Groups were compared by Kruskal-Wallis test. The horizontal middle line represents the median and $95 \%$ confidence interval $(\mathrm{Cl})$. Significant difference between groups at $\mathrm{p}<0.05$. A significant difference is observed between $\mathrm{G} 1-\mathrm{PKU}$ and G2-HPA, $\mathrm{P}<0.05$. 


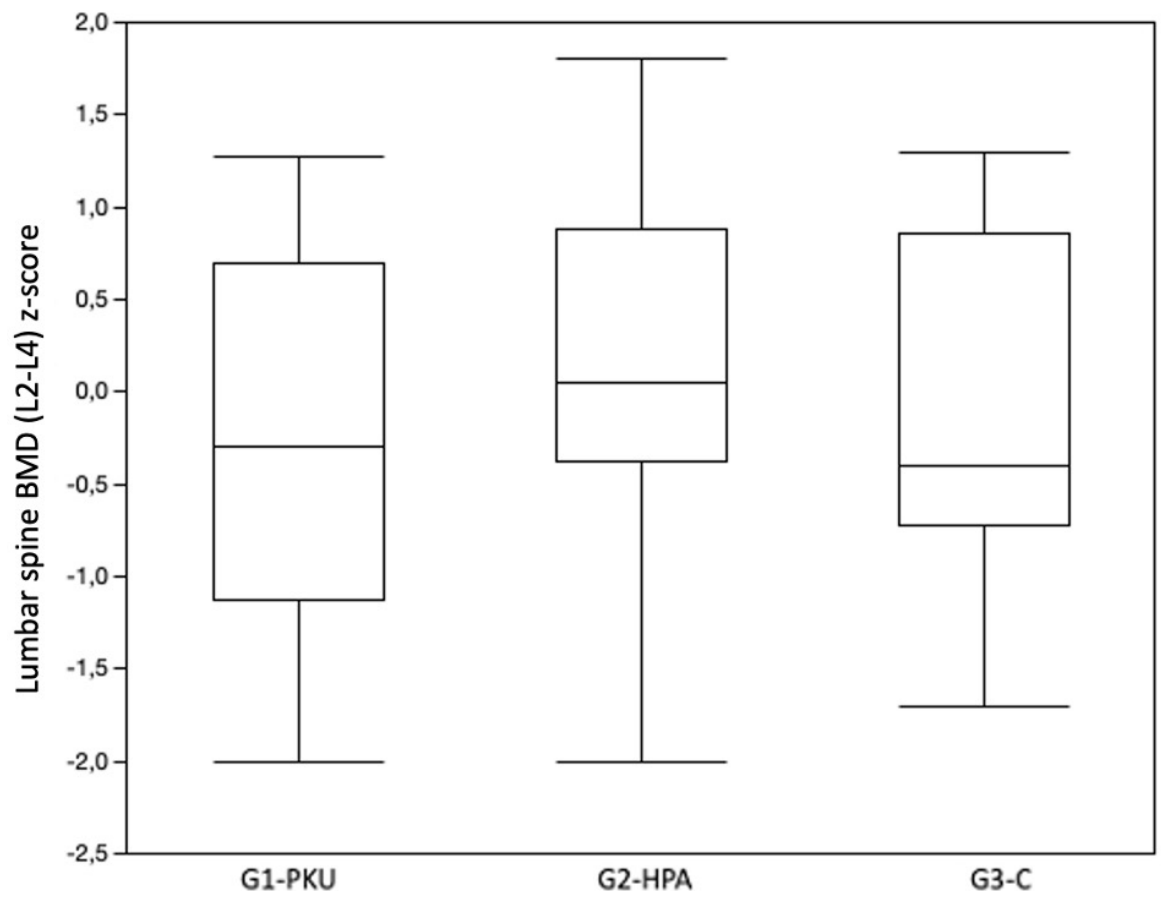

Figure 2. Z-score bone mineral density for each group. Z-score lumbar spine BMD for three groups of patients: Group 1: PKU, Group 2: HPA and Group 3: Control $(n=48)$. Groups were compared by Kruskal-Wallis test. The horizontal middle line represents the median and $95 \%$ confidence interval $(\mathrm{Cl})$. Significant difference between groups at $p<0.05$. There is no significant difference between groups.

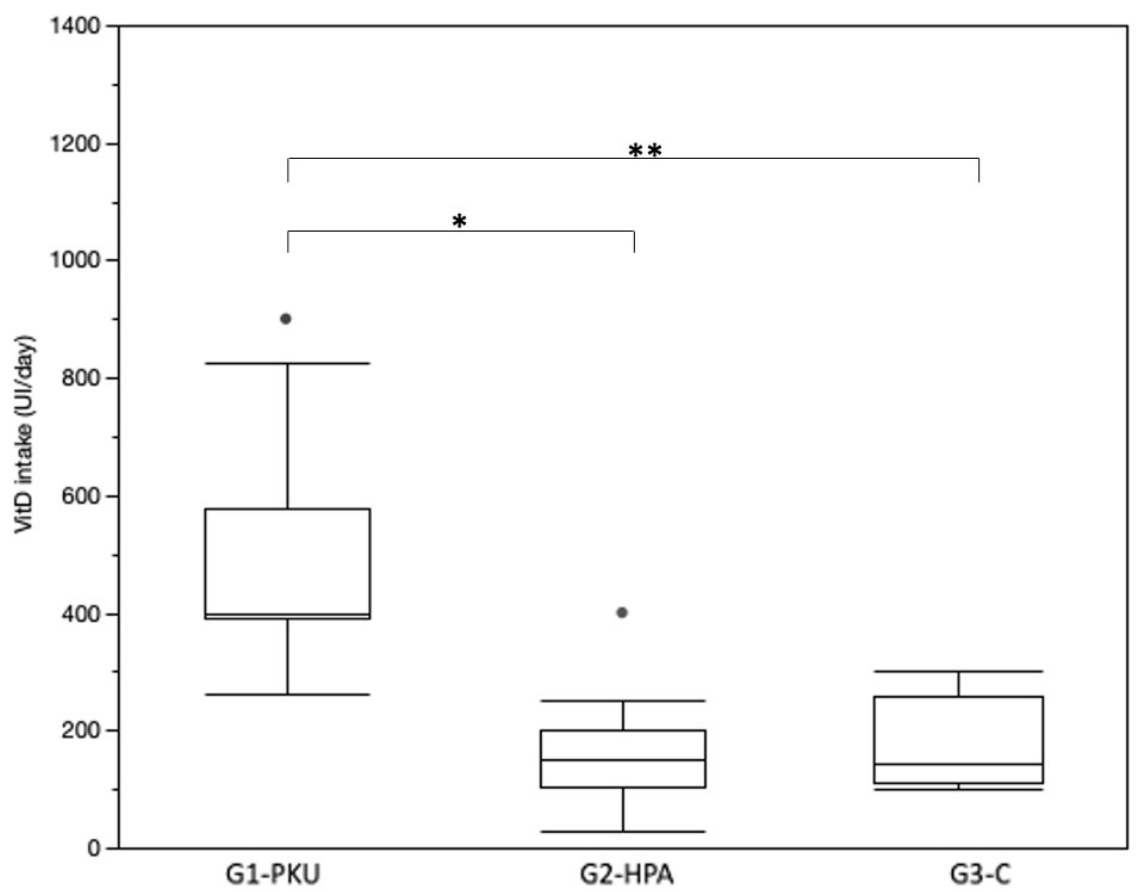

Figure 3. Intake Vitamin D for groups. Intake vitamin D for three groups of patients: Group 1: PKU, Group 2: HPA and Group 3: Control (n = 48). Groups were compared by Kruskal-Wallis test. The horizontal middle line represents the median and $95 \%$ confidence interval $(\mathrm{Cl})$. $\mathrm{A}$ significant difference is observed between G1-PKU and G2-HPA (* $\mathrm{p}=<0.05)$; G1- PKU and G3-C (** $\mathrm{p}=<0.05)$.

2507), G2-HPA= $744 \mathrm{mg} / \mathrm{day}(95 \% \mathrm{CI}, 610 ; 991)$ and G3-C=978 $\mathrm{mg} /$ day $(95 \% \mathrm{CI}, 724 ; 1032)$ of Ca, with statistically significant differences found between G1-PKU and G2-HPA $(\mathrm{p}<0.05)$ and between G1-PKU and G3-C (p<0.05) (Figure 4).
It is important to mention that the significant differences found in VitD intake and 25-OHD concentrations are maintained after performing a correction by sex, age, and pubertal stage among study groups. 


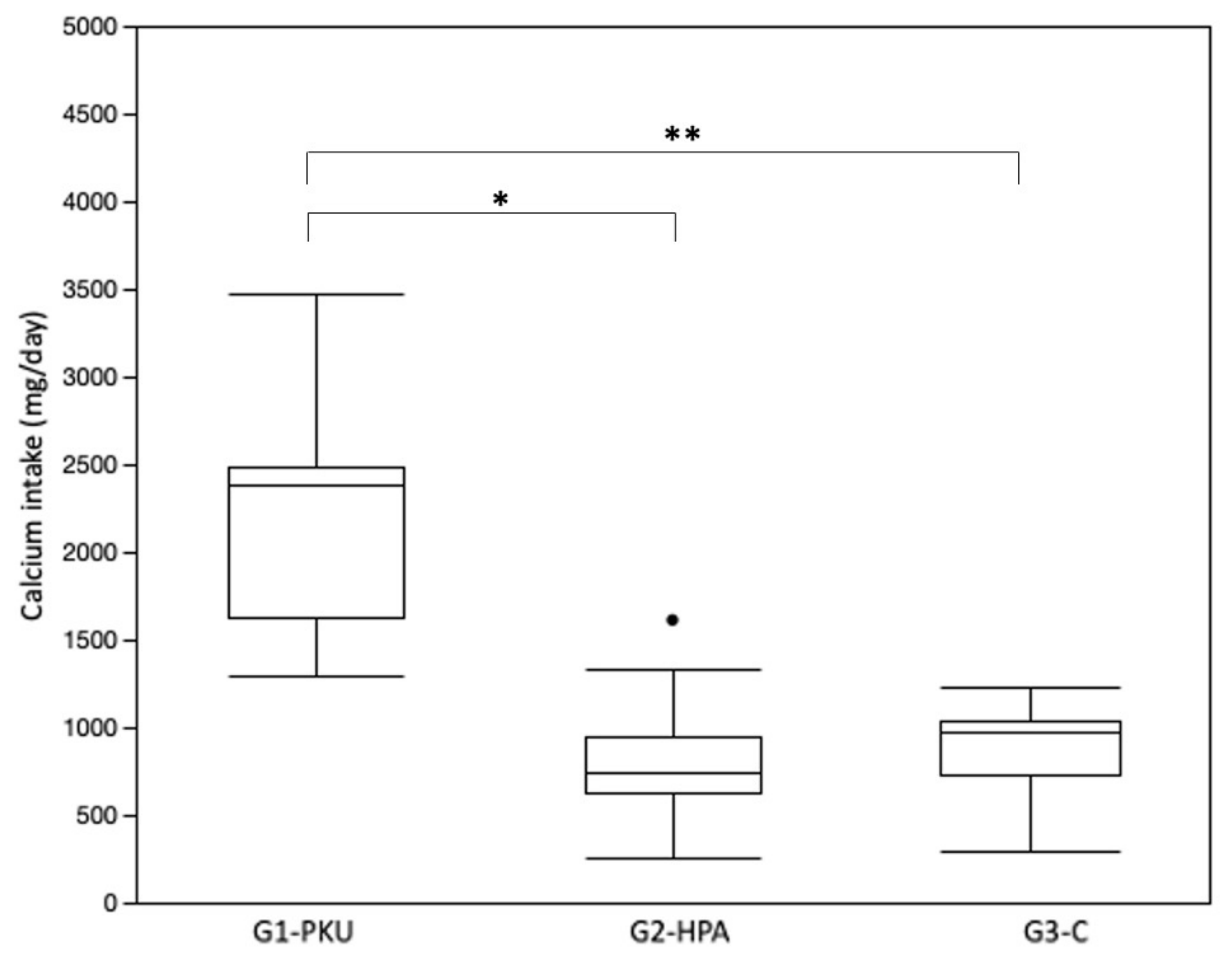

Figure 4. Intake Calcium for groups. Intake vitamin D for three groups of patients: Group 1: PKU, Group 2: HPA and Group 3: Control ( $\mathrm{n}=48$ ). Groups were compared by Kruskal-Wallis test. The horizontal middle line represents the median and $95 \%$ confidence interval (Cl). A significant difference is observed between G1-PKU and G2-HPA (* $\mathrm{p}=<0.05)$; G1- PKU and G3-C (** $\mathrm{p}=<0.05)$.

\section{Discussion}

Today, more than one billion people worldwide are deficient or insufficient in 25-OHD [29,30]. Chile is no exception, according to the latest 2016-2017 National Health Survey (ENS) [31], which studied a representative sample of women of childbearing age (WCBA) between 15 and 49 years old and older adults over 65 years old of both sexes: $52 \%$ of the WCBA and $59 \%$ of the older adults had some degree of 25-OHD deficiency, with no statistically significant difference by sex. From these analyses, it was revealed that in all regions of the country (i.e., from Arica to Magallanes), both in WCBA and in older adults, there is a prevalence of more than $2.5 \%$ of people with severe $25-\mathrm{OHD}$ deficiency. There are other studies, but not population-based, in which a $61 \%$ of deficiency has been found in pre-school children in Coyhaique [32] and a 97\% in school children in Punta Arenas [33]. In a recent study in Chile, children of both sexes in Antofagasta, Santiago and Concepción were found to have a 25-OHD deficiency of 78.5\%, $79.2 \%$ and $84.3 \%$, respectively (unpublished data).

There are some factors that play a fundamental role, such as: low-sun exposure due to long periods of time indoors, sedentism, air pollution, daily use of sunscreen and lower VitD synthesis in population living at latitudes higher than $30^{\circ}$ North or South where UVB rays are minimal, especially in autumn and winter. Other factors that may affect include: having a low dietary intake of foods rich in VitD, such as fatty fish and/or a low availability of fortified foods; having a lower skin synthesis of VitD due to age; as well as a lower synthesis due to dark skin pigmentation. Finally, it is important to mention that the increase in body fat decreases the concentrations of circulating 25-OHD concentration, with excessive weight (i.e., overweight and obesity) constituting another risk factor for 25 -OHD deficiency $[34,35,36]$. In the country of the study, several of the above-mentioned factors are present. It can be highlighted that from the city of Santiago towards the south of Chile (Santiago: latitude $33^{\circ}$ South) the population is at greater risk of deficiency of 25-OHD, the situation becomes critical in the extreme regions of Aysén and Magallanes. These mentioned risk factors that favor the deficiency of 25-OHD present in the Chilean population could explain the lower concentrations of 25-OHD found in the control group and the G2-HPA, in addition to a low intake of VitD in both groups [37].

In relation to the intake of $\mathrm{VitD}$, it is present in a limited number of foods: fatty fish, and fish liver oil and eggs, foods that are prohibited in the diet of PKU patients. Fatty fish are a good source of VitD containing 100-500 IU/portion; however, less than $10 \%$ of the Chilean population consumes fish at least twice a week (ENS 2016-2017)[38]. The Latin American Study on Nutrition and Health (ELANS) revealed an average VitD intake of $112 \mathrm{IU} /$ day $(2.8 \mu \mathrm{g} / \mathrm{day})$ in the Chilean population between 15 and 65 years old of both sexes, corresponding to $28 \%$ of the estimated average requirement of this vitamin (400 IU/day) [39]. Therefore, the usual diet of Chileans, which also does not have products adequately fortified with VitD, is insufficient to cover the population recommendations of the reference dietary intake of VitD. 
The prevalence of 25-OHD deficiency in patients with PKU varies according to the study conducted. However, most parts of the study agree that the deficiencies are similar between the $\mathrm{PKU}$ and control group. Deficiency figures ranging from $64 \%$ to $28 \%$ have been reported in the United States and nearly $20 \%$ in Japan[40]. In a systematic review and meta-analysis were included six cohort studies assessing 25-OHD. Among the studies, the findings varied by age group. Nevertheless, one of these, involving 31 adults with PKU, showed similar results to this research all patients had normal concentrations of 25-OHD [41].

In relation to the state of bone health in PKU, there is extensive literature. Coakley et al. [42]. found that $16 \mathrm{PKU}$ patients, out of 57, had a BMD z-score between (-1) and (-2.5) and three patients (5\%) had a $\mathrm{z}$-score below (-2.5). This decrease correlated positively with age, with an average of 17.5 years old. Another study analyzed the body composition of 48 patients with PKU and 32 patients with mild HPA, aged 5-18 years old. Both groups were compared with a healthy control group. BMD was significantly lower in patients with PKU (mean lumbar spine BMD z-score: $(+0.11)$; p-value $=0.03)$ and with mild HPA (mean lumbar spine BMD z-score: $(-0.34)$; p-value $=0.01$ ) [43]. Some studies report a relationship between reduced BMD and inadequate micronutrient intake, suggesting that reduction in BMD in PKU patients may be secondary to dietary treatment [44]. In this study, no statistically significant differences were found among the medians of lumbar spine, femur, and total BMD. This could be attributed to the fact that the PKU cohort of this study maintains a permanent follow-up and treatment with excellent adherence to PS consumption without Phe. In the case of PTH a marker of bone turnover, there are no differences between the groups: The serum values remain within the normal range in all cases and the distribution is similar in all groups, as has been seen in other studies [45].

Scientific evidence has shown that one of the factors influencing BMD is the 25-OHD serum concentrations. Thus, it is stated that the higher the concentrations of 25-OHD is, the better the BMD, and vice versa. Two studies carried out on patients with $\mathrm{PKU}$, which incorporated measurement of the concentrations of 25-OHD, reported a positive association between the serum concentrations of 25-OHD and BMD in children and adults [46] .Another study also detected a significant positive association between BMD and 25-OHD concentrations. In this study, it was found that G1-PKU had values of 25-OHD within normal ranges, and G3-C had a limit value of what is recommended. It is important to point out that G2-HPA presented values of this vitamin below the recommended concentrations, becoming a group at greater risk of presenting symptoms and signs of hypovitaminosis $\mathrm{D}$, such as bone mineral deficiency in the medium or long term $[46,47]$. The VitD intake and 25-OHD concentrations are very important because the VitD is an indispensable nutrient for $\mathrm{Ca}$ absorption, especially in situations of intestinal Ca deficit or decrease. It also regulates renal Ca loss and thus, Ca utilization is improved [48]. Several studies have improved BMD in PKU patients through Ca supplements and oral vitamin $\mathrm{D}[49,50]$. In this sense, the G1-PKU in this study showed a higher intake of $\mathrm{Vit} \mathrm{D}$ and $\mathrm{Ca}$, as patients consumed on average: $400 \mathrm{IU} /$ day of VitD (cholecalciferol or VitD3) and 2,507 $\mathrm{mg}$ /day of $\mathrm{Ca}$ (calcium carbonate, phosphate, and citrate). In the G1-PKU, 14 patients cover the daily requirements established by the EAR for VitD and everybody fulfills the EAR for calcium. Chilean PKU patients receive PS without Phe daily and for life, these are universally subsidized by the Chilean State and are the only source of vitamin $\mathrm{D}$ in their diet. They contain an average of 400-450 IU of VitD/100g per product, which could explain why PKUs in treatment, with good adherence to the diet, and with daily consumption of PS without Phe, had normal values of $25-\mathrm{OHD}(>32 \mathrm{ng} / \mathrm{mL})$ and a BMD, in most cases, normal. It is important to emphasize that G2-HPA had a VitD intake of $150 \mathrm{IU} /$ day, considered insufficient according to the EAR recommendations, and that it agrees with the low concentration of 25-OHD (28.1 ng / mL), considered deficient $(<30 \mathrm{ng} / \mathrm{mL}$ ). The same situation happened in the G3-C group with respect to VitD intake, since there is only one patient in both groups who fulfills the recommendation intake according to the EAR. This low intake was related to the fact that they do not consume foods fortified with VitD as is the case with PKU patients, because current Chilean legislation does not establish VitD fortification as mandatory [51]. This finding shows the importance of conducting further studies in the G2-HPA, as it would appear to be the most vulnerable group of having micro and macronutrient deficiencies.

In regards to the diet treatment adherence, it was determined in the G1-PKU that the median concentrations of plasma Phe was $310 \mathrm{umol} / \mathrm{L}$, which is considered good adherence since the Chilean protocol establishes between 120 and 360 umol/L, as target values for this age group [52]. It should be noted that this protocol is more demanding than the one of other populations, for example, the European Union protocol recommends maintaining Phe concentrations $<600 \mathrm{umol} / \mathrm{L}$ in children over 12 years old [53]. If this cut-off point is extrapolated to Chilean children, three G1-PKU patients would be outside this recommended range [54].

It should be noted that one of the weaknesses of this study could be the sample size of the G1-PKU and G2-HPA groups, which could lead to dispersion of the results obtained, both by age and by reference values. As PKU is a rare disorder, double-blind, controlled studies cannot be used in this cohort, as treatment for these patients is vital in the prevention of intellectual disability. Therefore, it is suggested to continue with prospective studies that provide us with more accurate metabolic status not only of Phe concentrations but of other macro- and micronutrients in people with PKU under treatment during different stages of life, and thus be able to prevent alterations caused by nutritional restrictions.

\section{Conclusions}

The results of this study have demonstrated the importance of the neonatal diagnosis of PKU, of long-term follow-up, good adherence to nutritional treatment and permanent consumption 
of PS without Phe, which become a fundamental pillar in the prevention of other pathologies with nutrient deficiencies, which could cause adverse effects on the quality of life of people with PKU.

Based on the results obtained in this study, it is imperative to carry out medical and nutritional follow-up, not only the group with PKU, but it should also be considered to carry out clinical evaluations to the subjects with HPA to detect early deficiencies or excesses of nutrient and that in the long term could affect your quality of life.

Due to the benefit of VitD and Ca intake over BMD, it is important to determine whether this benefit is maintained in the long term, especially in post-menopausal stages in followup PKU women.

In summary, it is essential to maintain adequate long-term follow-up in people with PKU and HPA, in order to assess nutrient intake and plasma concentrations of nutrients essential for good nutrition being able to determine early on whether the supplementation of any of these nutrients is necessary, to contribute to adequate growth and development of patients throughout the life cycle.

\section{Acknowledgments}

To the people with phenylketonuria and hyperphenylalaninemia and their families, who participated in this study to contribute to science.

\section{Declaration of Conflicting Interests}

The authors declared no potential conflicts of interest with respect to the research, authorship, and/or publication of this article.

\section{References}

1. Shoraka HR, Haghdoost AA, Baneshi MR, Bagherinezhad Z, Zolala F. Global prevalence of classic phenylketonuria based on neonatal screening program data: systematic review and meta-analysis. Clin Exp Pediatr. 2020;63(2):3443. doi: 10.3345/kjp.2019.00465

2. Cornejo V, Raimann E, Cabello JF, et al. Past, present and future of newborn screening in Chile. J Inherit Metab Dis. 2010;33 Suppl 3:S301-S306. doi: 10.1007/s10545010-9165-8

3. Geiger KE, Koeller DM, Harding CO, Huntington KL, Gillingham MB. Normal vitamin D concentrations and bone mineral density among children with inborn errors of metabolism consuming medical food-based diets. Nutr Res. 2016;36(1):101-108. doi: 10.1016/j.nutres.2015.11.007

4. Kose E, Arslan N. Vitamin/mineral and micronutrient status in patients with classical phenylketonuria. Clin Nutr. 2019;38(1):197-203. doi: 10.1016/j.clnu.2018.01.034
5. Pérez-Dueñas B, Cambra FJ, Vilaseca MA, Lambruschini N, Campistol J, Camacho JA. New approach to osteopenia in phenylketonuric patients. Acta Paediatr. 2002;91(8):899904. doi: 10.1080/080352502760148603

6. Allen JR, Humphries IR, Waters DL, et al. Decreased bone mineral density in children with phenylketonuria. Am J Clin Nutr. 1994;59(2):419-422. doi: 10.1093/ajcn/59.2.419

7. Demirdas S, van Spronsen FJ, Hollak CEM, et al. Micronutrients, essential fatty acids and bone health in phenylketonuria. Ann Nutr Metab. 2017;70(2):111-121. doi: 10.1159/000465529

8. Hossein-nezhad A, Holick MF. Vitamin D for health: a global perspective. Mayo Clin Proc. 2013;88(7):720-755. doi: 10.1016/j.mayocp.2013.05.011

9. Pfotenhauer KM, Shubrook JH. Vitamin D deficiency, its role in health and disease, and current supplementation recommendations. J Am Osteopath Assoc. 2017;117(5):301305. doi: 10.7556/jaoa.2017.055

10. Arnson Y, Amital H, Shoenfeld Y. Vitamin D and autoimmunity: new aetiological and therapeutic considerations. Ann Rheum Dis. 2007;66(9):1137-1142. doi: 10.1136/ard.2007.069831

11. Autier P, Boniol M, Pizot C, Mullie P. Vitamin D status and ill health: a systematic review. Lancet Diabetes Endocrinol. 2014;2(1):76-89. doi: 10.1016/S2213-8587(13)70165-7

12. Hansdottir S, Monick MM. Vitamin D effects on lung immunity and respiratory diseases. Vitam Horm. 2011;86:217-237. doi: 10.1016/B978-0-12-3869609.00009-5

13. Harms LR, Burne THJ, Eyles DW, McGrath JJ. Vitamin $\mathrm{D}$ and the brain. Best Pract Res Clin Endocrinol Metab. 2011;25(4):657-669. doi: 10.1016/j.beem.2011.05.009

14. National Health and Nutrition Examination Survey. NHANES 2007-2008 examination data. Centers for Disease Control and Prevention. https://wwwn.cdc.gov/nchs/ nhanes/continuousnhanes/default.aspx?BeginYear $=2007$ Published 2014. Accessed January 10, 2021.

15. Demirdas S, Coakley KE, Bisschop PH, Hollak CEM, Bosch AM, Singh RH. Bone health in phenylketonuria: a systematic review and meta-analysis. Orphanet J Rare Dis. 2015;10:17. doi: 10.1186/s13023-015-0232-y

16. Pérez-Dueñas B, Cambra FJ, Vilaseca MA, Lambruschini N, Campistol J, Camacho JA. New approach to osteopenia in phenylketonuric patients. Acta Paediatr. 2002;91(8):899904. doi: 10.1080/080352502760148603

17. Castro G, Hamilton V, Cornejo V. Chilean Nutrition Management Protocol for Patients With Phenylketonuria. J Inborn Errors Metab Screen. 2017;5:e160058. doi: $10.1177 / 2326409816689788$ 
18. Programa Salud Cardiovascular. Manejo alimentario del adulto son sobrepeso u obesidad. Chile: OPS/OMS; 2002. https://buenaspracticasaps.cl/wp-content/uploads/2014/07/ MINSAL-2002-manejo-alimentario-SP-OB.pdf. AAccessed January 10, 2021.

19. World Health Organization. Patrones de crecimiento de escolares y adolescentes entre 5 años 1 mes y 19 años (OMS 2007). https://www.who.int/growthref/en/. Accessed January 10, 2021.

20. Crocker PR, Bailey DA, Faulkner RA, Kowalski KC, McGrath R. Measuring general concentrations of physical activity: preliminary evidence for the physical activity questionnaire for older children. Med Sci Sports Exerc. 1997;29(10):13441349. doi: 10.1097/00005768-199710000-00011

21. Holick MF, Binkley NC, Bischoff-Ferrari HA, et al. Evaluation, treatment, and prevention of vitamin $\mathrm{D}$ deficiency: an endocrine society clinical practice guideline. $J$ Clin Endocrinol Metab. 2011;96(7):1911-1930. doi: 10.1210/ jc.2011-0385

22. Lewiecki EM, Gordon CM, Baim S, et al. International society for clinical densitometry 2007 adult and pediatric official positions. Bone. 2008;43(6):1115-1121. doi: 10.1016/j.bone.2008.08.106

23. Pérez-Dueñas B, Cambra FJ, Vilaseca MA, Lambruschini N, Campistol J, Camacho JA. New approach to osteopenia in phenylketonuric patients. Acta Paediatr. 2002;91(8):899904. doi: 10.1080/080352502760148603

24. Gordon CM, Bachrach LK, Carpenter TO, et al. Dual energy X-ray absorptiometry interpretation and reporting in children and adolescents: the 2007 ISCD pediatric official positions. JClin Densitom. 2008;11(1):43-58. doi: 10.1016/j. jocd.2007.12.005

25. Ward LM, Glorieux FH. The spectrum of pediatric osteoporosis. In: Glorieux FH, Pettifor JM, Jüppner H eds. Pediatric bone: biology and diseases. San Diego, CA: Academic Press 2003; 401-442.

26. Warren FM, Andersen PE, Wax MK, Cohen JI. Intraoperative parathyroid hormone concentrations in thyroid and parathyroid surgery. Laryngoscope. 2002;112(10):18661870. doi: 10.1097/00005537-200210000-00031

27. Castro G, Hamilton V, Cornejo V. Chilean nutrition management protocol for patients with phenylketonuria. J Inborn Errors Metab. 2017;5:e160058. doi: 10.1177/232 6409816689788

28. Zaror VG. Guía de la composición nutricional de alimentos naturales, de la industria y preparaciones chilenas habituales. 1st ed. Chile: Universidad de Chile - INTA; 2008.

29. Naeem Z. Vitamin D deficiency- an ignored epidemic. Int J Health Sci (Qassim). 2010;4(1):V-VI.
30. González G, Alvarado JN, Rojas A, Navarrete C, Velásquez CG, Arteaga E. High prevalence of vitamin D deficiency in chilean healthy postmenopausal women with normal sun exposure: additional evidence for a worldwide concern. Menopause. 2007;14(3 Pt 1):455-461. doi: 10.1097/ GME.0b013e31802c54c0

31. Ministerio Nacional de Salud. Encuesta Nacional de salud 2016-2017. 2018. http://epi.minsal.cl/wp-content/ uploads/2018/03/Resultados-Vitamina-D.pdf. Accessed June 1, 2020.

32. Le Roy C, Reyes M, González JM, Pérez-Bravo F, CastilloDurán C. Estado nutricional de vitamina D en pre escolares chilenos de zonas australes. Rev Med Chil. 2013;141(4)435441. doi: 10.4067/S0034-98872013000400003

33. Brinkmann K, Le Roy C, Iñiguez G, Borzutzky A. Deficiencia severa de vitamina $D$ en niños de Punta Arenas, Chile: influencia de estado nutricional en la respuesta a suplementación. Rev Chil Pediatr. 2015;86(3):182-188. doi: 10.1016/j.rchipe.2015.03.001

34. Pilz S, März W, Cashman KD, et al. Rationale and plan for vitamin D food fortification: a review and guidance paper. Front Endocrinol (Lausanne). 2018;9:373. doi: 10.3389/ fendo.2018.00373

35. Schmid A, Walther B. Natural vitamin D content in animal products. Adv Nutr. 2013;4(4):453-462. doi: 10.3945/ an. 113.003780

36. Holick MF. Vitamin D deficiency. $N$ Engl J Med. 2007;357(3):266-281. doi: 10.1056/NEJMra070553

37. Leiva C, Borzutzky A, Le Roy C, Rojas L. 2020. Deficiencia de vitamina $\mathrm{D}$ : propuesta de modelo chileno para una política nacional de fortificación alimentaria. Temas de la Agenda Pública. 2020;15(124):1-18.

38. Maira PM, Solar AP. Encuesta nacional de salud, ENS 2016-2017: un aporte a la planificación sanitaria y políticas públicas en Chile. ARS MEDICA. 2018;43(1):30-34. doi: 10.11565/arsmed.v43i1.1354

39. Fisberg M, Kovalskys I, Gómez G, et al. Latin American study of nutrition and health (ELANS): rationale and study design. BMC Public Health. 2016;16:93. doi: 10.1186/ s12889-016-2765-y

40. Montoya GAP, Singh RH, Cetinyurek-Yavuz A, Kuhn M, MacDonald A. Status of nutrients important in brain function in phenylketonuria: a systematic review and metaanalysis. Orphanet J Rare Dis. 2018;13(1):101. doi: 10.1186/ s13023-018-0839-X

41. Demirdas S, Coakley KE, Bisschop PH, Hollak CEM, Bosch AM, Singh RH. Salud ósea en fenilcetonuria: revisión sistemática y metanálisis. Orphanet J Rare Dis. 2015;10:17. doi: 10.1186/s13023-015-0232-y 
42. Coakley KE, Douglas TD, Singh RH. Using predictive modeling to estimate bone mineral density in children and adults with phenylketonuria. In: Osteoporosis International 2013, Conference: Interdisciplinary symposium on osteoporosis 2013 - Patient-centered care: Developing successful bone health teams, ISO 2013 Chicago, IL United States.

43. Doulgeraki A, Skarpalezou A, Theodosiadou A, Monopolis I, Schulpis K. Body composition profile of young patients with phenylketonuria and mild hyperphenylalaninemia. Int J Endocrinol Metab. 2014;12(3):e16061. doi: 10.5812/ijem.16061

44. de Groot MJ, Hoeksma M, van Rijn M, Slart RHJA, van Spronsen FJ. Relationships between lumbar bone mineral density and biochemical parameters in phenylketonuria patients. Mol Genet Metab. 2012 Apr;105(4):566-570. doi: 10.1016/j.ymgme.2012.01.006

45. Hillman L, Schlotzhauer C, Lee D, et al. Decreased bone mineralization in children with phenylketonuria under treatment. Eur J Pediatr. 1996;155 Suppl 1:S148-S152. doi: $10.1007 / \mathrm{pl} 00014234$

46. Coakley KE, Douglas TD, Singh RH. Using predictive modeling to estimate bone mineral density in children and adults with phenylketonuria. In: Osteoporosis International 2013, Conference: Interdisciplinary symposium on osteoporosis 2013 - Patient-centered care: Developing successful bone health teams, ISO 2013 Chicago, IL United States.

47. Nagasaka H, Tsukahara H, Takatani T, et al. Cross-sectional study of bone metabolism with nutrition in adult classical phenylketonuric patients diagnosed by neonatal screening. J Bone Miner Metab. 2011;29(6):737-743. doi: 10.1007/ s00774-011-0276-6
48. Cortina LS, Villares JMM, Suárez VM, et al. Ingesta y fuentes de calcio en una muestra representativa de escolares españoles (estudio CADO). An Pediatr (Barc). 2011;27(3):715-723. doi: 10.1016/j.anpedi.2010.07.001

49. Koura HM, Ismail NA, Kamel AF, Ahmed AM, SaadHussein A, Effat LK. A long-term study of bone mineral density in patients with phenylketonuria under diet therapy. Arch Med Sci. 2011;7(3):493-500. doi: 10.5114/ aoms.2011.23417

50. Pérez-Dueñas B, Cambra FJ, Vilaseca MA, Lambruschini N, Campistol J, Camacho JA. New approach to osteopenia in phenylketonuric patients. Acta Paediatr. 2002;91(8):899904. doi: 10.1080/080352502760148603

51. Ministerio de Salud. Resolución exenta $N^{\circ} 393 / 02$. Fija directrices nutricionales sobre uso de vitaminas y minerales en alimentos. Chile: Diario oficial. 2002; p. 1-7.

52. Castro G, Hamilton V, Cornejo V. Chilean nutrition management protocol for patients with phenylketonuria. J Inborn Errors Metab. 2017;5:e160058. doi: 10.1177/232 6409816689788

53. van Wegberg AMJ, MacDonald A, Ahring K, et al. The complete European guidelines on phenylketonuria: diagnosis and treatment. Orphanet J Rare Dis. 2017;12(1):162. doi: 10.1186/s13023-017-0685-2

54. Hofman DL, Champ CL, Lawton CL, Henderson M, Dye L. A systematic review of cognitive functioning in early treated adults with phenylketonuria. Orphanet J Rare Dis. 2018;13(1):150. doi: 10.1186/s13023-018-0893-4 